\title{
Redesign Taman Kota Kabupaten Bogor Dengan Pendekatan Urban Landscape Design
}

\author{
IRFAN ADI PERMANA, INDUNG SITTI FATIMAH²* \\ 1. Departemen Arsitektur Lanskap, Fakultas Pertanian, Institut Pertanian Bogor, \\ Dramaga, Bogor 16680, Indonesia \\ 2. Divisi Perencanaan dan Desain Arsitektur Lanskap, Institut Pertanian Bogor, Dramaga \\ Bogor, 16680, Indonesia \\ *E-mail: isfatimah.ïn@gmail.com
}

\section{ABSTRACT \\ Redesign Bogor District City Park with Urban Landscape Design Approach}

Urban landscape design is an approach on designing a city which gives positive impact on its civilians by providing a habitable environment. Urban landscape comes in many form, one of them is city park. City park one of the facilitation provided by the city where people can do several activities inside. A city park also serve as a landmark of the city. Bogor district has several parks with recreational function but not many city parks available that serves as a public space. One of them are a park located near the central government of Bogor district. The purpose of this study was to redesign a functional, aesthetic city park that could also be a landmark on the district. This study use spatial and descriptive analysis method.

Keywords: Bogor district, city park, urban landscape design

\section{Pendahuluan}

Kabupaten Bogor dapat dikategorikan sebagai kawasan perkotaan, khususnya daerah Kecamatan Cibinong yang merupakan pusat pemerintahan. Kecamatan Cibinong berkembang pesat, laju pembangunan dalam berbagai sektor diantaranya bisnis dan industri. Hal tersebut dapat dilihat dari pesatnya pembangunan perkotaan berupa bangunan pabrik dan pusat perbelanjaan/department store. Kabupaten Bogor memiliki sejumlah taman yang umumnya berfungsi sebagai tempat wisata, seperti Taman Safari, Taman Matahari, dan Taman Bunga Nusantara, namun taman-taman tersebut tidak dapat dinikmati oleh semua kalangan masyarakat. Padahal, di Kabupaten Bogor terdapat taman kota yang dapat digunakan tanpa harus mengeluarkan biaya atau gratis yaitu taman kota Tegar Beriman yang terletak di kawasan pusat pemerintahan Kabupaten Bogor, tetapi karena kondisinya yang kurang menarik, taman tersebut kurang menarik perhatian masyarakat.

Sejak selesai masa pembangunannya, taman mengalami masalah diantaranya: karena bentukan desainnya, taman agak sulit terlihat, pengunjung yang datang pun tidak dari semua kalangan masyarakat. Menururut rapim dan utomo (2008) dalam mendesain 
sesuatu secara ideal, dikenal istilah form must follow function, bentuk mengikuti fungsinya, yang berarti setiap benda harus direncanakan dan di desain sebaik mungkin untuk bisa berfungsi optimal. Taman ini memliki air mancur dengan ukuran yang cukup besar dan tinggi, cukup mudah terlihat tetapi sulit dinikmati. Taman tersebut memliki sejumlah elemen taman yang sudah terbangun, namun kurang punya daya tarik bagi masyarakat, terutama dari kalangan masyarakat urban. Masyarakat urban disebut urbanitas, berasal dari bahasa latin 'Urbs' yang artinya orang bebas dan beradab, tempat yang bermasyarakat, berbudaya, dan berpemerintah (Wiryomartono 2002), oleh karena itu perlu dilakukan sebuah desain ulang pada taman kota untuk memberikan rekomendasi desain yang memenuhi kebutuhan masyarakat urban.

Konsep urban lanskap design dinilai mampu menciptakan kebutuhan ruang fisik kepada manusia dengan berbagai macam desain yang beragam dan baru, tegas dan konsisten serta sustainable. Desain yang beragam mampu memberikan makna yang berbeda kepada setiap manusia dan memberikan suasana tersendiri bagi manusia (Booth, 1998). Kegiatan penelitian ini bertujuan untuk 1) mengidentifikasi tapak dan menganalisis potensi dan kendala tapak yang telah dijadikan sebuah taman kota dan 2) mendesain ulang Taman Kota Tegar Beriman Kabupaten Bogor.

\section{Metode}

\section{Lokasi dan Waktu}

Penelitian dilaksanakan di Taman Kota Tegar Beriman yang sudah terbangun di Cibinong, Kabupaten Bogor, Jawa Barat. Taman berada di depan kantor bupati Kabupaten Bogor (Gambar 1).

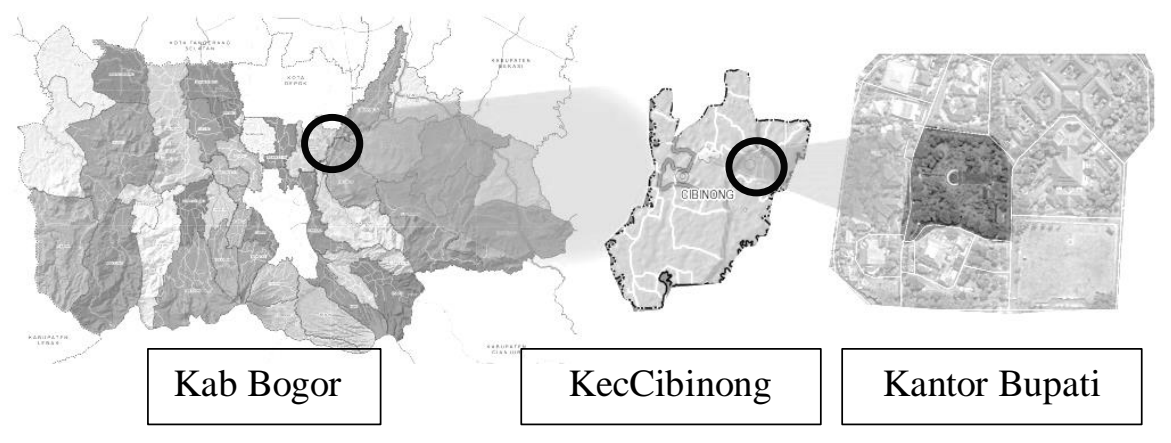

Gambar 1. Peta lokasi penelitian (BAPPEDA, 2012)

\section{Metode Penelitian}

Metode yang digunakan pada peneltian ini adalah sebagai berikut :

1. Inventarisasi

Survey lapang wawancara dan pembagian kuisioner 20 kuisioner. Data basemap, fisik bio-fisik, dan sosial. Pengumpulan data sekunder (DKP Kabupaten Bogor/Pekerjaan umum dill).

2. Analisis-Sintesis

Analisis dilakukan terhadap aspek fisik maupun bio-fisik dan menghasilkan potensi serta kendala pada taman kota di Kabupaten Bogor.

3. Perancangan

Pertama melakukan diagram fungsi keterhubungan taman. Tahapan kedua concept plan yaitu pembuatan konsep yang dibagi menjadi konsep dasar dan konsep desain, 
menghasilkan blockplan, siteplan, planting plan. Tahapan ketiga hasilkan gambar potongan, gambar detail, perspektif dan animasi.

\section{Hasil Dan Pembahasan \\ 3.1 Kondisi umum}

Lokasi penelitian secara administratif berada di Kecamatan Cibinong yaitu di pusat pemerintahan Kabupaten Bogor, lokasi penelitian pada sebuah taman kota yang sering disebut Taman Kota Tegar Beriman, posisi taman tersebut berada di pusat pemerintahan kota bogor dengan kepemilikan/ di bawah tanggung jawab oleh Dinas Kebersihan dan Pemakaman Kabupaten Bogor.

Secara geografis taman terletak pada koordinat $6^{\circ} 28^{\prime} 45.92^{\prime \prime L S}$ dan 106²9'24.65"BT dengan batas wilayah; Jalan Indah di sebelah Utara, Jalan raya Tegar Beriman di sebelah Selatan, Jalan Bersih di sebelah Barat, Jalan Pemda di sebelah Timur. Taman dapat diakses dari jalan raya Tegar Beriman atau dari arah Jalan Cipayung dan menuju Jalan Bersih.

Suhu udara rata-rata pada kawasan Kecamatan Cibinong adalah $25,93^{\circ} \mathrm{C}$. Tingkat kelembaban nisbi udara pada taman ini rata-rata sebesar 82,83\%. Kecepatan angin pada Kecamatan Cibinong rata-rata yaitu sebesar 3,9. Curah hujan Kecamatan Cibinong berkisar antara 3000-4000 mm3/tahun. Jenis batuan yang berada pada Kecamatan Cibinong merupakan jenis batuan endapan permukaan sedangkan jenis tanah merupakan jenis tanah latosol merah latosol coklat kemerahan.

Taman tersebut memiliki topografi datar pada keseluruhan area dengan ketinggian 443.484 meter diatas permukaan laut (mdpl) serta saluran drainase pada taman memliki sistem drainase tertutup. Saluran drainase tersebut merupakan outlet yang bermuara di danau pada bagian timur taman yang berjarak sekitar $391 \mathrm{~m}$. Pada kondisi di dalam taman aliran run off tidak berfungsi secara maksimal untuk mengalirkan air limpasan sehingga air hujan tidak semuanya mengalir menuju drainase utama yang berada di sekeliling taman.

Vegetasi yang terdapat dalam taman penelitian antara lain adalah teh-tehan, siklok, rumput gajah, bismarck palm, bismarck palm, kana, lili paris, hanjuang, serai wangi, drasena, beringin, kerai payung, gint falase agave (inggris), pacing, kuca), Yellow walking iris, Paku jejer, palem hijau,kihujan, pucuk merah, ketapang kencana, palem ekor tupai.

\subsection{Analisis dan Sintesis}

Aksesibilitas dan Sirkulasi

Akses menuju taman dapat ditempuh dengan berjalan kaki, menggunakan kendaraan pribadi atau umum. Taman terhalang oleh masjid raya Kabupaten Bogor serta tidak ada papan pengarah, signage atau identitas serta area parkir taman. Pada bagian welcome area utama untuk masyarakat terletak pada Jalan Bersih (bagian barat) taman dengan kondisi terhalang pedagang kaki lima serta kondisi gerbang yang seharusnya terbuka dengan lebar gerbang $5 \mathrm{~m}$ hanya dibuka dengan lebar $1 \mathrm{~m}$ saja.

Pada aspek desain pembuatan sebuah taman seharusnya didukung dengan fasilitas umum seperti parkir maupun papan pengarah serta signage yang mudah oleh pengguna. perlu adanya penataan pedagang kaki lima pada bagian luar taman sehingga taman dapat terlihat dengan jelas dari arah jalan bersih.

Pemandangan (View)

Good view terlihat pada bagian penanaman tanaman pohon, semak, ground cover dan rumput. Adanya pola penanaman yang berulang serta penggunaan jenis vegetasi yang sama membuat vegetasi terlihat rapih. 
Bad view pada taman dapat terlihat pada bangunan air mancur dengan tinggi sekitar $5 \mathrm{~m}$ dan diameter kolam 20m. Air mancur sudah tidak berfungsi seperti awal pembangunan, kini kondisi kolam bocor dan air mancur tidak mengalir. Kerusakan air mancur tersebut membuat air mancur tampak seperti corong besar. Amphiteatre yang pada garis desainnya menghadap ke arah air mancur namun kondisi tersebut banyak terhalang oleh vegetasi tegakan pohon bahkan terdapat satu tegakan pohon yang berada di tengah-tengah.



Gambar 2. Peta analisis view

\section{Kenyamanan Iklim}

Empat elemen dasar penyusun untuk mendesain taman dengan memperhatikan iklim mikro ialah temperatur udara, kelembaban, radiasi matahari dan pergerakan angin (Brooks 1988).Menurut Motloch (2001) Vegetasi pohon berukuran besar dan menengah dapat pengubah iklim mikro yang efektif. Vegetasi tersebut memberikan keteduhan dari tinggi tajuk pohon dan dari sudut penyinaran matahari. Aliran udara merupakan ventilasi udara menggunakan vegetasi.

\section{Vegetasi}

Vegetasi sebagai desain

a. Spatial Enclosure : Taman memliki luasan kurang lebih 1.2 hektar, seharusnya kesan terbuka harus diperlihatkan agar terkesan luas oleh user.

b. Spatial Type : ruang memliki banyak tipe dari yang sangat tertutup sampai publik. Hal tersebut dipengaruhi oleh permainan garis vertical dan horizontal.

c. Spatial Depth : komposisi ruang lebih efektif apabila menggabungkan foreground, middle ground, dan background.

d. Enframement : kosmposisi vegetasi dapat membuat sebuah bingkai view, dan dapat mengarahkan pandangan user menuju focal point. 
e. Plant material and Landform : landform dapat dibentuk dari pemakaian material tanaman. Misalnya penanaman yang padat pada landform tinggi akan menambahkan kesan visual tinggi dan membentuk kesan tertutup. Pembentukan vegetasi sebagai landform pada taman tidak dapat dijumpai dikarenakan kondisi datar, permainan ketinggian vegetasi sebagai pembentuk landform harus didukung dengan kondisi topografi pada taman tersebut.

\section{Topografi dan Hidrologi}

\section{Landform as line}

Persepsi pada landform sangat dipengaruhi oleh tipe atau karakter garis pada lanskap contohnya garis angular biasanya menghasilkan perasaan yang kuat energi dan ketegasan.Disisi lain, garis yang lengkung memberikan rasa ketenangan kepasifan dan relaxsasi. Seorang desainer dapat memodifikasi landform dengan menerapkan ilmu arsitek sehingga landform yang dihasilkan akan sangat terstruktur. Landform yang natural dapat melembutkan keberadaan sebuah ruang jika dikombinasikan dengan landform datar atau bersudut sehingga menghasilkan sebuah landform yang dinamis.Taman kota Tegar Beriman memiliki tofografi yang cenderung datar pada semua bagian adapun satu sudut bagian taman memliki landform yang berbeda dengan perbedaan sekitar 10$15 \mathrm{~cm}$.Perubahan landform dapat dimodifikasi dari hal lain seperti perkerasan, border, bangku taman dan elemen taman lainnya. Maka dari itu landform pada taman harus diubah dengan bentukan yang bersudut agar menimbulkan kesan enerjik.
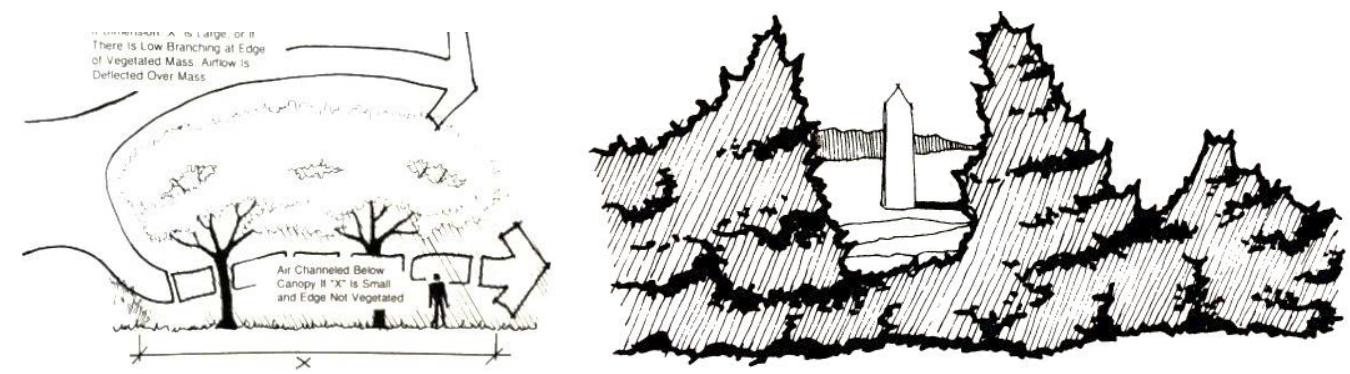

Gambar 3. Fungsi Vegetasi terhadap Iklim (kiri) dan Vegetasi sebagai Enframement (kanan) (Motloch, 2006)

\section{Analisis Sosial}

Elemen taman yang paling penting adalah bangku taman. Banyak perilaku user yang menyimpang dengan menggunakan elemen taman yang lain dijadikan tempat duduk dan beristirahat seperti : dinding pembatas, planter box, pagar dll. User lebih menyukai tempat duduk yang memanjang disebabkan antar user tidak saling mengenal sehingga duduk berjauhan. Menurut Rutledge (1981) setiap orang yang duduk dibangku taman memliki jarak diantara mereka sehingga harus mengakomodasi kebutuhan fisik tersebut. 

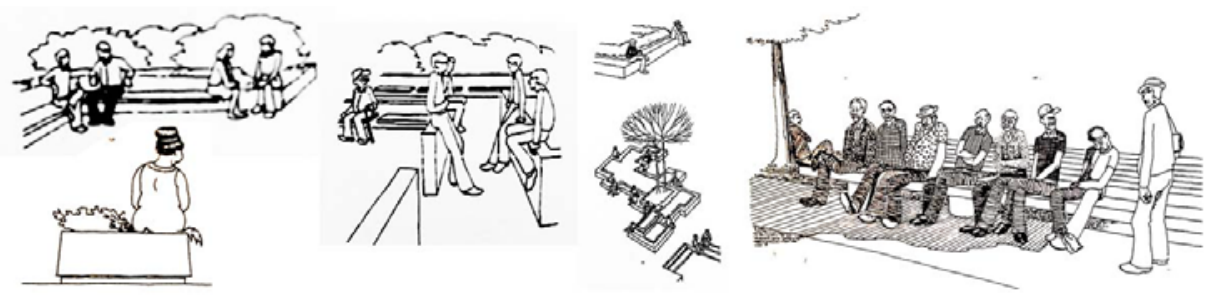

Gambar 4. Perilaku Pengguna di dalam Taman (Rutledge, 1981)

\subsection{Konsep}

\section{Konsep Dasar}

Perubahan perilaku penggunan taman yang mulai berkurang bukan hanya karena faktor fasilitas yang sudah tidak mendukung lagi melainkan adanya faktor perubahan kebiasaan masyarakat yang semakin modern. Perubahan tersebut disebut urbanisasi atau perubahan perilaku dari desa ke kota atau sering disebut zaman modern, urbanisasi berasal dari kata urban yang artinya sifat ke kota. Perpindahan tersebut bukan hanya sebatas perpindahan geografis melainkan adanya perubahan kebiasaan, perilaku, kepuasan sesorang terhadap sesuatu yang terus bertambah.Menurut (Alain Grnier 1984) urbanisasi adalah suatu proses pengembangan dan konsentrasi ruang terbangun. Taman kota merupakan ruang terbangun yang sengaja dibangun untuk kebutuhan ruang publik. Sebuah taman haruslah menyatukan antara orang dengan perekonomian rendah dan orang dengan perekonmian tinggi sehingga tidak adanya kesenjangan. Adapun beberapa tahapan dalam mengusung taman kota Tegar Beriman menjadi pusat perhatian diantaranya: menjadikan taman kota sebagai landmark, tidak adanya kesenjangan pengguna, memberikan bentukan design yang mewah serta modernisasi dengan konsep urban landscape design, dan kesan rumah didalam taman.

\section{Konsep Desain}

Konsep desain yang diterapkan yaitu mengadopsi dari urban landscape design, kata urban dikaitkan dengan sebuah gedung-gedung perkotaan yang menjulang tinggi, apabila dilihat secara keseluruhan maka tersusun garis-garis yang membentuk sebuah pandangan perspektif. Umunya garis perspektif dalam pandangan manusia terdiri dari satu titik, dua titik dan seterusnya tergantung dari sudut mana arah pandangannya. Konsep desain yang diterapkan yaitu garis perspektif yang di transformasi ke dalam tiga titik sehingga sumber garis akan menjadi tiga bagian yang disebar.Pola yang akan tersusun dari garis-garis tersebut akan terkesan acak dan berantakan namun tetap unity.

\section{Konsep Ruang dan Fasilitas}

Ruang utama focal point merupakan ruang yang berada di tengah-tengah taman, ruang tersebut berfungsi sebagai pusat atraksi yang dihasilkan oleh air mancur yang telah dimofifikasi sebelumnya, dan akan ada perubahan baik itu dari bentuk, warna, dan komposisi material, oleh karena itu ruang atama akan menjadi pusat perhatian didukung oleh atraksi lighting, pengunjung dapat bermain air dan menyentuh struktur air mancur maupun berphoto di spot2 tertentu. 


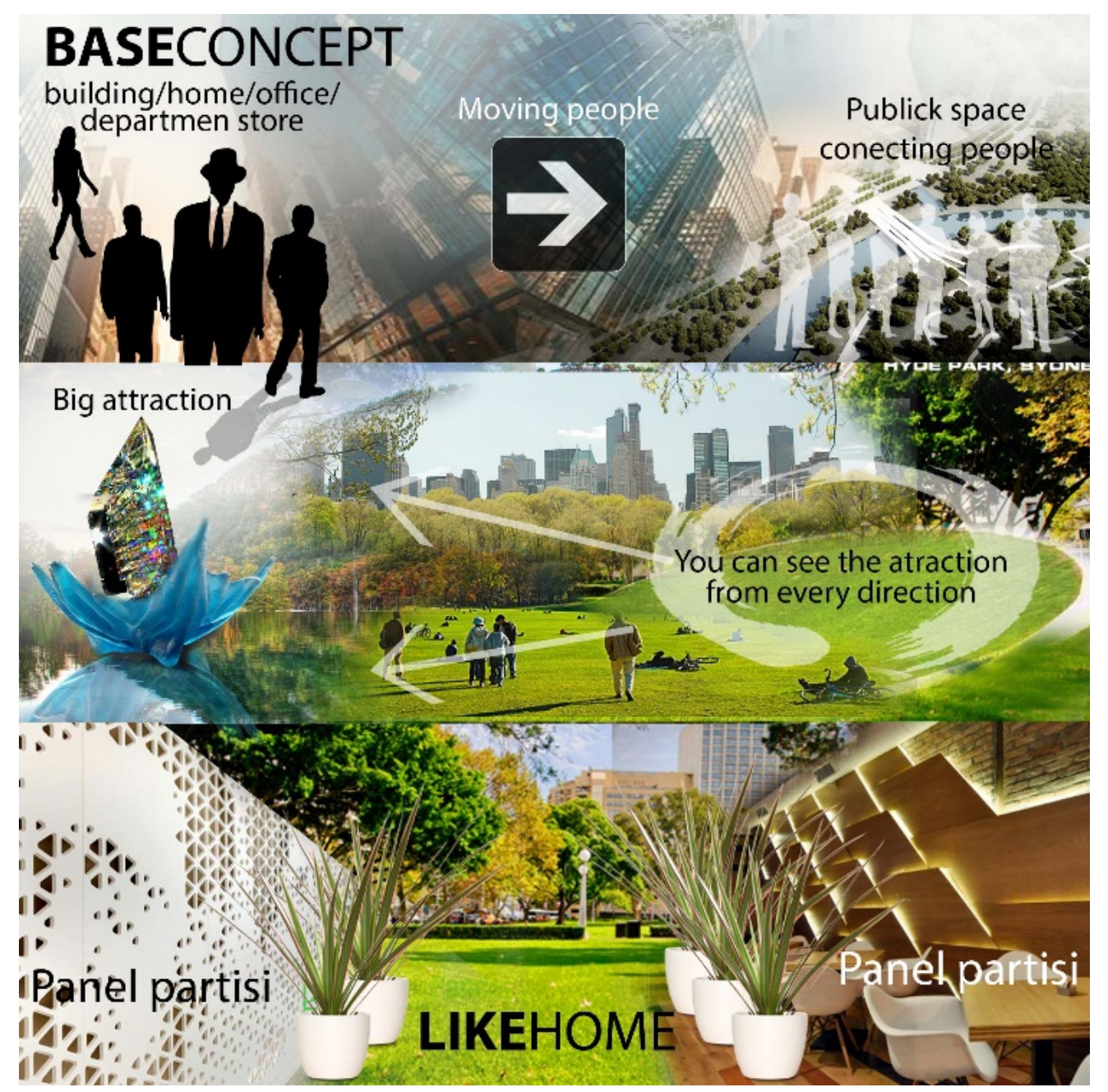

Gambar 5. Ilustrasi Konsep Dasar

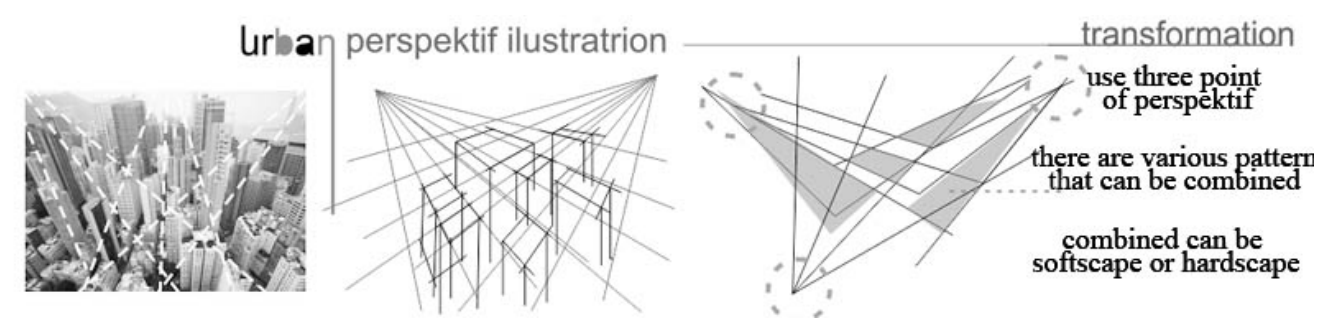

Gambar 6. Ilustrasi Konsep Desain

Ruang komunitas merupakan ruang dimana orang-orang dengan golongan yang sama dapat berkumpul dalam satu tempat dan mampu mewadahi ekspresi mereka, perkembangan kreativitas akan terus bertambah terutama di kalangan remaja dan dewasa oleh karena itu ruang komunitas merupakan suatu ruang dimana orang dapat bertemu satu sama lain dalam jumlah individu yang banyak, perubahan konsep yang akan ditrapkan yaitu pola bangku taman yang menyebar dengan pola terpusat sehingga daya tampungnya akan semakin bertambah. 
Ruang rekreasi dibagi menjadi dua sub-ruang yaitu ruang sosial dan ruang privat. Ruang sosial merupakan ruang dimana semua user dapat bertemu dalam satua area yang luas dan tidak adanya batasan border baik itu oleh semak maupun perkerasan. Terdapat sebuah landform yang menanjak sebagai daya tarik, sub-ruang sosial disusun oleh permainan pola rumput dengan perkerasan namun didominasi lebih oleh rumput, subruang privat yaitu ruang dengan fasilitas bangku taman dengan kapasitas terbatas dengan hanya beberapa bangku taman. Terdapat partisi dengan desain yang menarik.

Ruang olah raga merupakan tempat bagi pengunjung untuk melakukan aktifitas olah raga, konsep ruang olahraga yang diterapkan meliputi olahraga seperti : basket 3 on 3 , mini futsal, senam dan mini skate board. Suatu taman hendaknya memliki sebuah tempat untuk ruang aktif seperti olah raga terutama di daerah perkotaan, kebutuhan manusia akan ruang untuk berolah raga sangatlah tinggi, konsep yang diterapkan serba minimalis mengingat taman ini tidak memliki ruang yang cukup luas..

\section{Konsep Sirkulasi}

Angular geometry dibentuk sudut selain $90^{\circ}$, komposisi tersebut memberikan rasa energetik dan dinamis.Sudut tajam mampu meningkatkan energi, sementara sudut tumpul memberi kesan terkontrol. Komposisi angular dengan sudut tumpul yang saling bertemu dapat memberikan perasaan yang sangat terkontrol dan teratur. Material yang digunakan berupa perkerasan pavement atau conblock.Circular geometry adalah sebuah jejak dari point yang berpindah-pindah yang mengelilingi titik pusat pada jarak tertentu yang terkesan positif. Penggunaan tipe pola angular geometry dan circular geometry dipengaruhi oleh aktifitas user, perilaku user cenderung sprawi atau menyebar.Pola circular geometry sebagai guide line yang jelas dapat menuntun user menuju berbagai ruang sehingga terlihat jelas bahwa user akan dibebaskan didalam taman dalam pemilihan jalur.

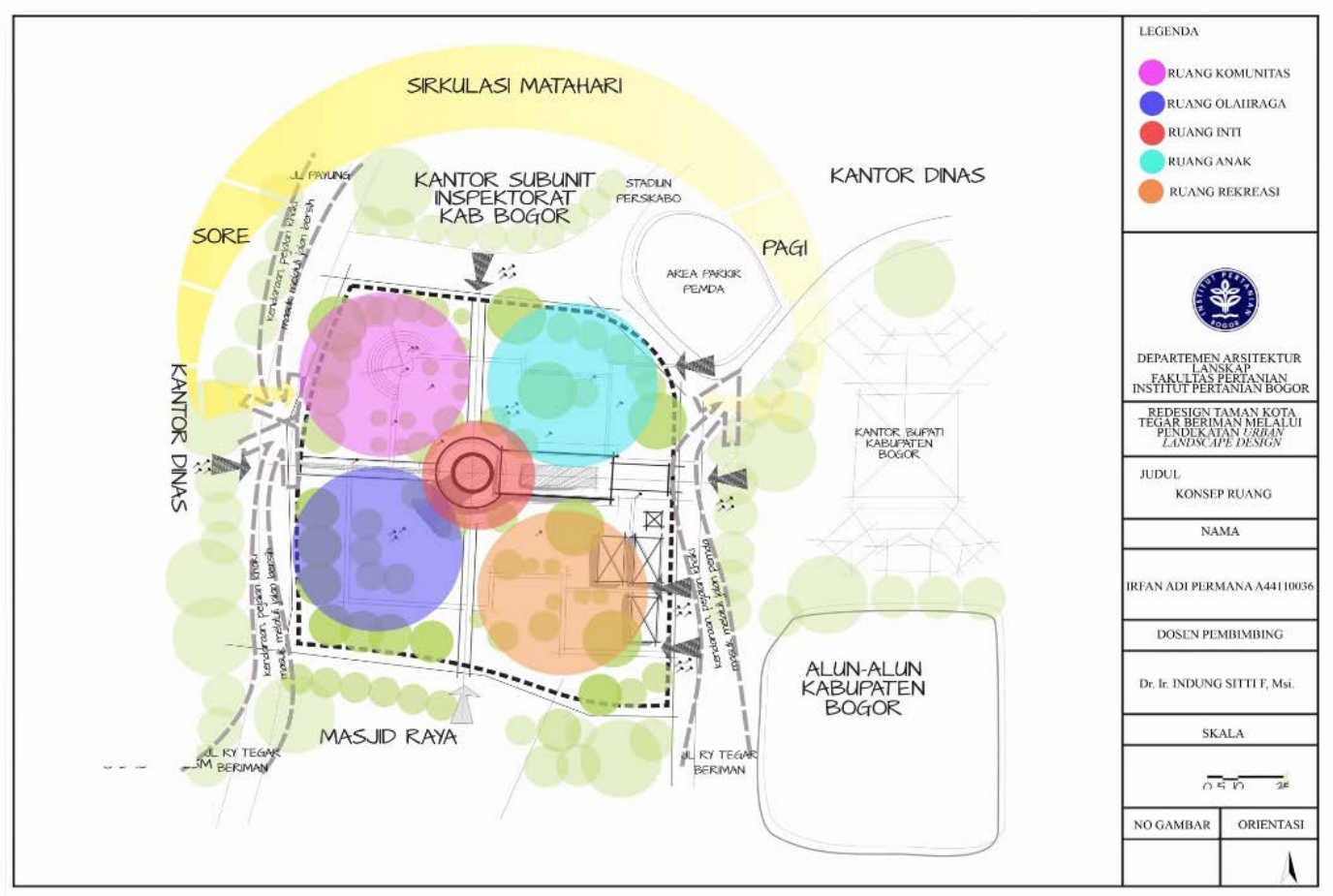

Gambar 7. Ilustrasi Konsep Ruang 


\section{Konsep Vegetasi}

Tanaman menjadi pohon dengan tajuk kecil dan berdaun jarum hal ini akan lebih efisian ini, penggunaan tajuk pohon berdaun jarum digunakan karena diameter 1-1.5m membuat cahaya matahari akan lebih mudah menembus vegetasi di bawahnya seperti semak dan groundcover.

Vegetasi semak dan groundcover berbunga digunakan sebegai konsep estetika taman, konsep bunga yang diterapkan bukan tanaman sekulen melainkan tanaman bunga yang tahan lama, berbatang, tidak mudah rusak, serta mampu menambah keindahan taman.Vegetasi peneduh menggunakan pohon eksisting yang sudah berada di taman sebelumnya namun dilakukan pengurangan pada beberapa titik.

\section{Konsep Penerapan Urban Landscape Design}

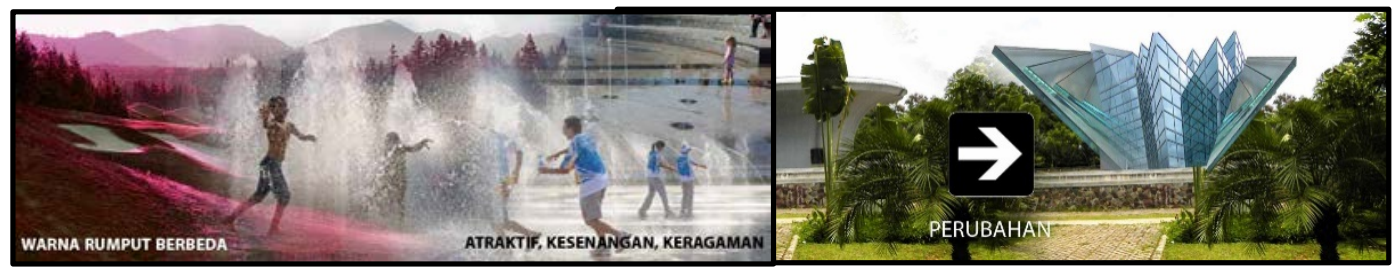

Gambar 8. Ilustrasi Penerapan Urban Landscape Design

Adapun beberapa aspek yang harus dipenuhi dalam urban design yaitu ;

1. Ruang untuk masyarakat

Untuk menciptakan tempat yang dicintai dan dimanfaatkan dengan maksimal, tempat tersebut harus aman, nyaman, bervariasi dan atraktif

2. Memperkaya keadaan sekarang

Pembangunan baru harus memperkaya kualitas tempat tempat urban yang ada.

3. Membuat koneksi

Sebuah ruang harus mudah di akses dan terintegrasi secara fisik dan visual dengan lingkungannya.

4. Bekerja dengan alam

Ruang yang dapat menyajikan keseimbangan lingkungan antara alam dan buatan manusia dengan penggunaan sumberdaya alam seperti ; klimat, landform, dan ekologi.

5. Menggabungkan kegunaan sesuai dengan bentukan.

tempat yang nyaman dan menyenangkan dan mempertemukan berbagai macam kebutuhan user dalam sekala besar.

6. Manajamen investasi

Agar sebuah proyek dapat dikembangkan dan diterima meraka harus secara ekonomi dapat dibangun, dikelola dan dipertahankan.

7. Desain untuk perubahan

Perkembangan baru harus cukup fleksibel untuk merespon tantangan di masa depan, gaya hidup dan demografi. 


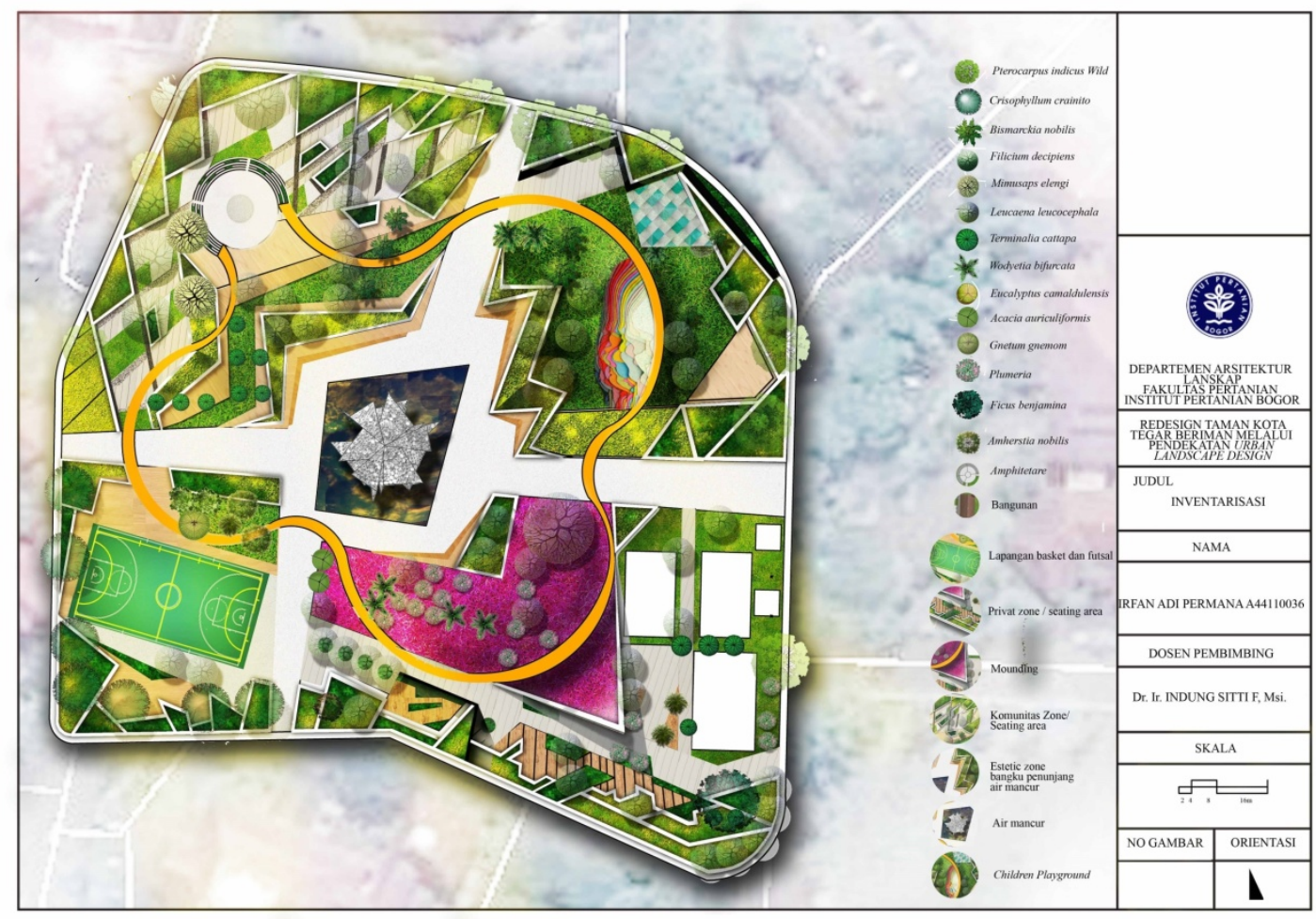

Gambar 9. Site Plan

\section{Simpulan}

Dalam pembangunan sebuah taman khususnya taman kota yang digunakan oleh semua kalangan masyarakat untuk berinteraksi satu sama lain hendaklah memeliki desain yang sesuai dengan kebutuhan pengunjungnya, sebuah desain yang memliki identitas serta karakter yang berbeda dari taman yang ada sebelumnya sehingga mampu mengundang daya tarik pengunjung, mampu memberikan contoh desain yang dapat ditiru dan diterapkan ketika mereka pulang sehingga ada keterhubungan atau rasa memliki. Tidak hanya itu sebuah taman haruslah memberikan kenyamanan, keamanan dan yang paling penting adalah keindahan. Urban landscape design secara garis besar yaitu memanfaatkan sumberdaya yang ada pada masa kini dan membentuknya atau ditrasnformasikan menjadi sebuah karya yang dapat dicintai oleh banyak orang karena pada dasarnya bentukan desain yang dihasilkan berdasarkan kebutuhan sumberdaya manusia itu sendiri. Urban design tidak akan pernah sama pada setiap masanya karena seiring waktu manusia mengalami perubahan.

\section{Daftar Pustaka}

Booth, N. K. 1983. Basic Element of Landscape Architecture Design. Waveland Press Inc, United States of America.

Brooks, RG. 1988. Site Planning: Environment, Process, and Development. Prentice-Hall, United States of America.

Motloch, JL. 2001. Introduction to landscape Design. John Wiley \& sons Inc, Canada. 